\title{
Urea Amperometric Biosensors Based on Nanostructured Polypyrrole and Poly Ortho-Phenylenediamine
}

\author{
Svetla Ivanova, Yavor Ivanov, Tzonka Godjevargova* \\ University "Prof. Assen Zlatarov", Burgas, Bulgaria \\ Email: "godjevargova@yahoo.com
}

Received December 20, 2012; revised January 23, 2013; accepted February 6, 2013

\begin{abstract}
Urea Amperometric biosensor was obtained on the base of nanostructured polypyrrole (PPy) and poly orthophenylenediamine (POPDA). The optimal conditions for monomer electropolymerization were determined. The effect of supporting electrolyte and number of deposition cycles on the OPDA and Py electropolymerization were studied. It was proved that POPDA and PPy were affected by $\mathrm{pH}$ changes and responded to the ammonium, product of urease catalyzed reaction. SEM images of the modified Pt/PPy electrode were presented. The cycle voltammograms and chrono amperometric curves of Pt/POPDA/urease and Pt/PPy/urease electrodes were studied. A good linear relationship was observed for Pt/POPDA/urease electrode in a concentration range from 6.7 to $54 \mathrm{mM}$ urea. For Pt/PPy/urease electrode the linear relation in the range from 0.02 to $0.16 \mathrm{mM}$ urea was determined. The entrapped carbon nanotubes $(\mathrm{CNT})$ in PPy film and the bipolymer layers were prepared for construction of $\mathrm{Pt} / \mathrm{PPy} / \mathrm{CNT} / \mathrm{urease}, \mathrm{Pt} / \mathrm{POPDA} / \mathrm{PPy} / \mathrm{urease}$ and $\mathrm{Pt} / \mathrm{PPy} / \mathrm{POPDA} /$ urease biosensors. Obviously, the addition of POPDA to the composition of the two biosensors (Pt/PPy/POPDA/urease and Pt/POPDA/PPy/urease) reduced their sensitivity to urea. Pt/PPy/CNT/urease and Pt/PPy/ urease biosensors were 173 and 138 times more sensitive to urea than biosensor without PPy (Pt/POPDA/urease biosensor). It was found, that the performance of Pt/PPy/CNT/urease electrode was the best from the five obtained biosensors: linear range of urea concentrations-from 0.02 to $0.16 \mathrm{mM}$; sensitivity- $15.22 \mu \mathrm{A} / \mathrm{mM}$ and detection limit$0.005 \mathrm{mM}$ urea.
\end{abstract}

Keywords: Biosensor; Urea; Urease; Electrodeposition; Polypyrrole; Poly Ortho-Phenylenediamine; Carbon Nanotubes

\section{Introduction}

The urea concentration in serum or urine is an indicator of kidney diseases, as well as diabetes, and analysis in clinical laboratories is frequently used. In a urea biosensor the enzyme urease, which catalyses the hydrolysis of urea to ammonia and carbonate can be immobilized into different transducers, such as conducting polymers. Various conducting polymers, like polyaniline (PANi), polypyrrole (PPy) and poly ortho-phenylenediamine, have been used for the fabrication of biosensors. Among them, polypyrrole is one of the most extensively used conducting polymers in the fabrication of urease biosensors [1]. The versatility of this polymer is determined by its biocompatibility, capability to transduce energy arising from the interaction of analytes and analyte recognizing sites into electrical signals that are easily monitored, capability to protect electrodes from interfering material, and easy way for electro-chemical deposition on the surface of any type of electrode.

As opposed to PPy, POPDA shows the conductivity in

"Corresponding author. its reduced state, whereas its oxidized state is insulating. This determines the electrochemical properties of POPDA, since many electrode redox processes of solution species have been shown to take place within relatively narrow potential window, corresponding to the reduced (conducting) form of this polymer [2]. Recently nanoparticles enhancing enzyme immobilization technique have become widespread. The using of carbon nanotubes (CNT) as mediators of the electron transfer from the enzyme molecules to the electrode surface is often applied. Their unique electronic properties suggest that CNT have the ability to promote the electron transfer reactions of biomolecules in electrochemistry [3]. Their mechanical properties, high-aspect ratio, electrical conductivity and chemical stability make CNT perfect for a wide range of applications that include fabrication of urease biosensors [4].

A variety of urease biosensors with high sensitivity and excellent reproducibility based on nanostructured polypyrrole [5-9], poly ortho-phenylenediamine [10,11] and carbon nanotubes $[12,13]$ has been reported.

The aim of this paper was to study the conditions for 
preparation of urea amperometric biosensor based on nanostructured polypyrrole, poly ortho-phenylenediamine, multi-layered nanostructured substrates and comparing the performance of obtained biosensors.

\section{Experimental}

\subsection{Reagents and Chemicals}

Pyrrole (Py), 98\% from Sigma-Aldrich, USA; orthophenylenediamine (OPDA) from Merck; urease EC 3.5.1.5, $112 \mathrm{U} \cdot \mathrm{mg}^{-1}$ from Fluka; carbon nanotubes (CNT) from Sigma Aldrich with size 2 - $6 \mathrm{~nm}$ and length 0.1 $10 \mu \mathrm{m}$, with $90 \%$ purity; glutaraldehyde from Merck. All reagents were of analytical grade. All solutions were prepared using deionized water from PURELAB Ultrasystem.

\subsection{Instrumentation}

Cyclic voltammetric, amperometric measurements and electropolymerization of Py and OPDA monomers on working electrode surface were carried out with the PalmSens Electrochemical Instrument (Palm Instruments BV, Netherlands) and three-electrode electrochemical cell: a platinum plate electrode $\left(1 \mathrm{~cm}^{2}\right.$ area) as a working electrode, platinum wire as a counter electrode and a saturated calomel (SCE) or $\mathrm{Ag} / \mathrm{AgCl}$ electrodes as reference electrodes were used both in the cyclic voltammetric and amperometric measurements.

\subsection{Cleaning of the Working Electrode Surface}

The working electrode was mechanically polished with 0.3 and $0.05 \mu \mathrm{m}$ alumina, rinsed with distilled water, acetone and once again with water. Then, it was cleaned electrochemically in $1 \mathrm{M} \mathrm{H}_{2} \mathrm{SO}_{4}$ by potential cycling between -0.25 and $+1.45 \mathrm{~V}$ versus $\mathrm{Ag} / \mathrm{AgCl}$ at a scan rate of $0.075 \mathrm{~V} / \mathrm{s}$ for 10 - $15 \mathrm{~min}$. Before electropolymerization, the monomer solutions (Py or OPDA) were purged with high-purity nitrogen gas for at least $10 \mathrm{~min}$ in order to remove dissolved oxygen. An inert environment was maintained in the electrochemical cell during the polymerization by purging the cell atmosphere with a flow of nitrogen.

\subsection{Preparation of $\mathrm{Pt} / \mathrm{POPDA} / \mathrm{U}$ rease Biosensor}

OPDA was electropolymerized by continuous potential cycling between -0.4 and $+1.0 \mathrm{~V}$ vs. SCE, at a scan rate of $0.05 \mathrm{~V} / \mathrm{s}$. The number of deposition cycles was varied (1, 10 and 20 cycles). The electropolymerization was carried out in $0.1 \mathrm{M} \mathrm{H}_{2} \mathrm{SO}_{4}$ or $0.1 \mathrm{M} \mathrm{KCI}$ as supporting electrolyte containing $0.05 \mathrm{M}$ OPDA monomer solution. Then, the working electrode was dried at room temperature. A $5 \mu \mathrm{L}$ of $25 \%$ glutaraldehyde was pipette on the electrode surface and the solution was allowed to evaporate at $30^{\circ} \mathrm{C}$ for $30 \mathrm{~min}$. The urease was immobilized on the POPDA surface by pipetting a $5 \mu \mathrm{L}$ of $0.1 \%$ urease and the electrode was dried at $4^{\circ} \mathrm{C}$.

\subsection{Preparation of $\mathrm{Pt} / \mathrm{PPy} / \mathrm{Urease}$ Biosensor}

The electropolymerization of Py was carried out in $0.1 \mathrm{M}$ $\mathrm{KCl}$ as supporting electrolyte, containing $0.1 \mathrm{M} \mathrm{NaCl}$ and $0.4 \mathrm{M}$ Py monomer solution. The final concentration of urease in this solution was $0.1 \%$. The working electrode potential was cycled in the potential range from -1.0 to $+0.7 \mathrm{~V}$ vs $\mathrm{Ag} / \mathrm{AgCl}$, at a scan rate of $0.05 \mathrm{~V} / \mathrm{s}, 30$ cycles.

\subsection{Preparation of Multi-Layered Nanostructured Urease Biosensor}

\section{- Pt/PPy/CNT/urease biosensor}

The electropolymerization of Py was carried out in 0.1 $\mathrm{M} \mathrm{KCl}$ as supporting electrolyte, containing $0.1 \mathrm{M} \mathrm{NaCl}$ and $0.4 \mathrm{M}$ Py monomer solution. $0.0016 \mathrm{~g}$ CNT were added and the mixture was homogenized by sonication for $1 \mathrm{~h}$. Then urease was added to this solution to a final concentration of $0.1 \%$. The working electrode potential was cycled in the potential range of -1.0 to $+0.7 \mathrm{~V}$ at a scan rate of $0.05 \mathrm{~V} / \mathrm{s}$ for 30 cycles.

\section{- Pt/POPDA/PPy/urease biosensor}

POPDA was deposited on working electrode by the method described above. After that the electrode was dried at room temperature and deposited the second polymer layer of PPy with entrapping urease, as described above.

\section{- Pt/PPy/POPDA/urease biosensor}

POPDA film was deposited on Pt/PPy/urease electrode by the method described above.

\subsection{Electrochemical Measurements with Urease Biosensor}

\section{- Cyclic voltammetry}

Cyclic voltammograms (CVs) of Pt/POPDA/urease electrode were carried out in $30 \mathrm{~mL}$ of $0.01 \mathrm{M} \mathrm{PBS}(\mathrm{pH}$ $5.8)$ in the absence and presence of $100 \mu \mathrm{L}$ of $1 \mathrm{M}$ urea. The working electrode potential was cycled in the potential range of -1.0 to $+1.5 \mathrm{~V}$.

Cyclic voltammograms of $\mathrm{Pt} / \mathrm{PPy} /$ urease electrode were carried out in $10 \mathrm{~mL}$ of $0.01 \mathrm{M}$ PBS ( $\mathrm{pH} 5.8)$, containing $0.1 \mathrm{M} \mathrm{NaCl}$, in the absence and presence of $200 \mu \mathrm{L}$ of $10 \mathrm{mM}$ urea. The working electrode potential was cycled in the potential range of -1.0 to $+0.7 \mathrm{~V}$.

\section{- Chronoamperometry}

Chronoamperometry was used as the transduction method for detecting urea in different solutions. The current density was measured for films potentiostatically 
polarized at a fixed potential $-0.1 \mathrm{~V}$ for Pt/POPDA/ urease and $-0.6 \mathrm{~V}$ for $\mathrm{Pt} / \mathrm{PPy} /$ urease biosensors, at successive addition of $100 \mu \mathrm{L}$ of $1 \mathrm{M}$ urea ( $\mathrm{pH}$ 5.8) and $200 \mu \mathrm{L}$ of $10 \mathrm{mM}$ urea ( $\mathrm{pH} 5.8$ ), respectively. This value of $\mathrm{pH}$ allowed us to achieve a condition of maximum activity of urease.

\section{Results and Discussion}

\subsection{Preparation of Pt/POPDA/Urease Biosensor}

The first step for developing of urea biosensor was to choose the optimum conditions for monomer electropolymerization. Several experiments have been carried out to obtain stable and active polymeric film. The effect of supporting electrolyte and number of deposition cycles on the OPDA electropolymerization were studied. Figure 1 shows the CVs of the OPDA electropolymerization $-0.05 \mathrm{M}$ OPDA in $0.1 \mathrm{M} \mathrm{KCl}$ (dashed line) and $0.05 \mathrm{M}$ OPDA in $0.1 \mathrm{M} \mathrm{H}_{2} \mathrm{SO}_{4}$ (solid line). The results demonstrated that the acidity of the electrolyte had a very strong effect on the electropolymerization process. The CV curve, obtained in $\mathrm{H}_{2} \mathrm{SO}_{4}$, is much wider compared with the $\mathrm{CV}$ curve obtained in $\mathrm{KCl}$. This is probably due to the different conductivity of POPDA film in both electrolytes. Thus, $0.1 \mathrm{M} \mathrm{H}_{2} \mathrm{SO}_{4}$ was chosen as supporting electrolyte for the OPDA electropolymerization.

Figure 2 shows CV curves of Pt/POPDA electrode as a function of different number of deposition cycles-1, 10 and 20. At 1 st deposition cycle a high and wide oxidation peak was appeared at $+0.70 \mathrm{~V}$. This was attributed to the oxidation of the monomer on the clean Pt electrode and formation of POPDA film. In the following negative sweep, a reduction peak at $-0.18 \mathrm{~V}$ was observed, which is much lower than the oxidation peak. At 10 deposition cycle the oxidation and reduction peaks were decreased. Besides that, with the increasing of number of deposition cycles, the anodic and cathodic peaks shifted to +0.54

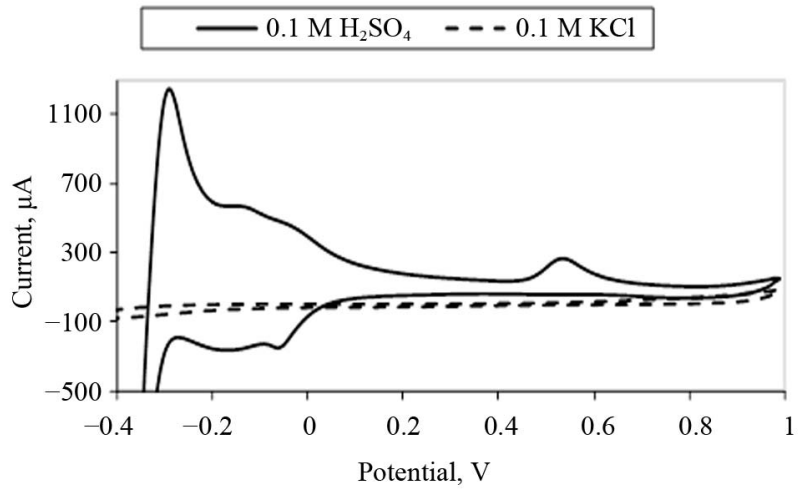

Figure 1. CVs of the electropolymerization of 0.05 M OPDA in $0.1 \mathrm{M} \mathrm{KCl}$ (dashed line) and $0.1 \mathrm{M} \mathrm{H}_{2} \mathrm{SO}_{4}$ (solid line). Scan rate: $0.05 \mathrm{~V} / \mathrm{s}$; potential range: from -0.4 to $+1.0 \mathrm{~V} ; 10$ cycles.

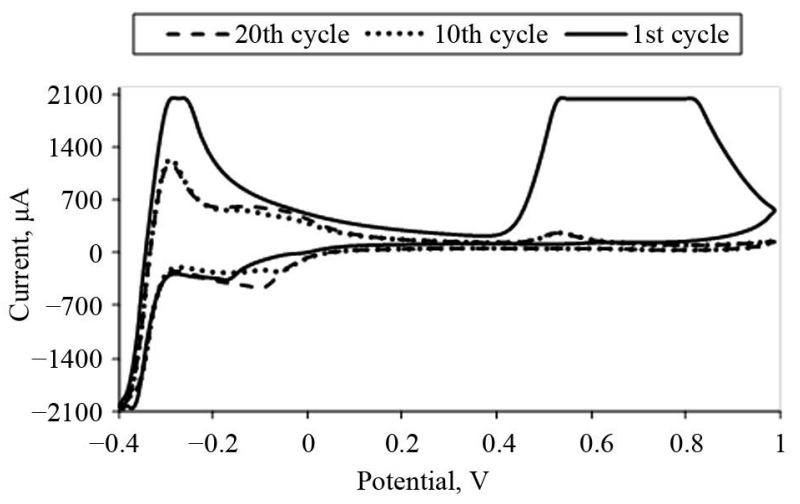

Figure 2. CVs of the electropolymerization of $0.05 \mathrm{M}$ OPDA in $0.1 \mathrm{M} \mathrm{H}_{2} \mathrm{SO}_{4}$. Scan rate: $0.05 \mathrm{~V} / \mathrm{s}$; potential range: from -0.4 to $+1.0 \mathrm{~V}$; (-) 1st cycle, (.....) 10th cycle and (- - -) 20th cycle.

and $-0.1 \mathrm{~V}$, respectively. At 20 deposition cycle the peaks were the same, like these ones at 10 deposition cycle. This means that the electropolymerization was autolimited process and 10 deposition cycles were optimal cycles for obtaining of stable polymer film.

The effect of $\mathrm{pH}$ of the solution on CVs of Pt/POPDA electrode was studied. Figure 3 shows $\mathrm{CV}$ curves of Pt/POPDA electrode, obtained at $\mathrm{pH} 4.5$ (0.1 M acetate buffer) and $\mathrm{pH} 8.5$ (0.1 M glycine buffer), at potential range from -1.0 to $+1.0 \mathrm{~V}$, scan rate of $0.05 \mathrm{~V} / \mathrm{s}$. The results showed that the magnitude (in $\mu \mathrm{A}$ ) of oxidation and reduction peaks of $\mathrm{CV}$ curves was affected by $\mathrm{pH}$ solution. The $\mathrm{CV}$ curve, obtained at $\mathrm{pH} 4.5$ is much wider compared with the CV curve obtained at $\mathrm{pH} 8.5$. This proved that POPDA was affected by $\mathrm{pH}$ changes and will respond to the ammonium, product of urease catalyzed reaction. Therefore, POPDA is suitable matrix for immobilization of urease.

The hydrolysis of urea, which can be catalyzed by urease, yields a typical increase in $\mathrm{pH}$ of the medium from ammonia, product of enzyme reaction (Figure 4).

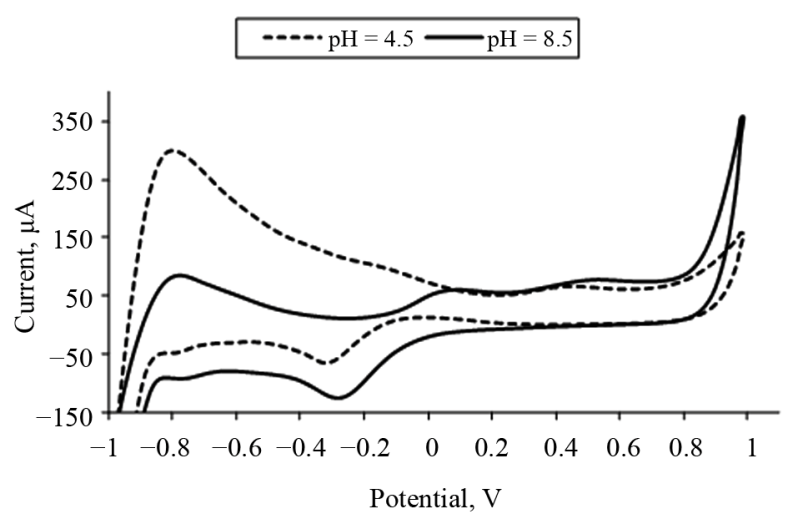

Figure 3. CVs of Pt/POPDA electrode in buffer solutions with pH 4.5 (dashed line) and pH 8.5 (solid line); potential range: from -1.0 to $+1.0 \mathrm{~V}$, scan rate of $0.05 \mathrm{~V} / \mathrm{s}$. 


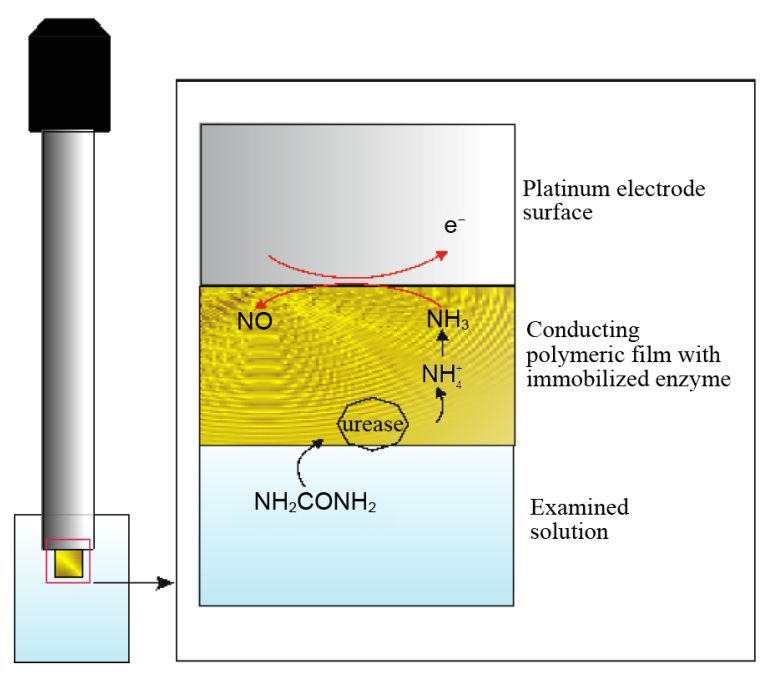

Figure 4. Urea detection by conducting polymer-based amperometric biosensor.

Urea biosensor is the typical example of biocatalytic amperometric biosensor where ammonium ion interacts with polymer to induce a change in conductivity of the polymer.

The interactions of conducting polymer with ammonia are also documented in the literature $[14,15]$, which offers strong evidence that reversible deprotonation of the polymer structure takes place, while a concomitant increase in the $\mathrm{pH}$ of the medium can be detected electrochemically.

The CVs of Pt/POPDA/urease electrode in $30 \mathrm{~mL}$ of $0.01 \mathrm{M}$ PBS ( $\mathrm{pH} 5.8$ ) without and with $100 \mu \mathrm{L}$ of $1 \mathrm{M}$ urea were studied (Figure 5). Figure 5 shows that the magnitude (in $\mu \mathrm{A})$ of oxidation $(-0.4 \mathrm{~V}$ ) and reduction $(-0.1 \mathrm{~V})$ peaks of $\mathrm{CV}$ curves reduced after addition of urea. These changes clearly showed that the biosensor responds to the urea. Therefore, the potentials for our amperometric study were chosen as -0.4 and $-0.1 \mathrm{~V}$ (working potentials).

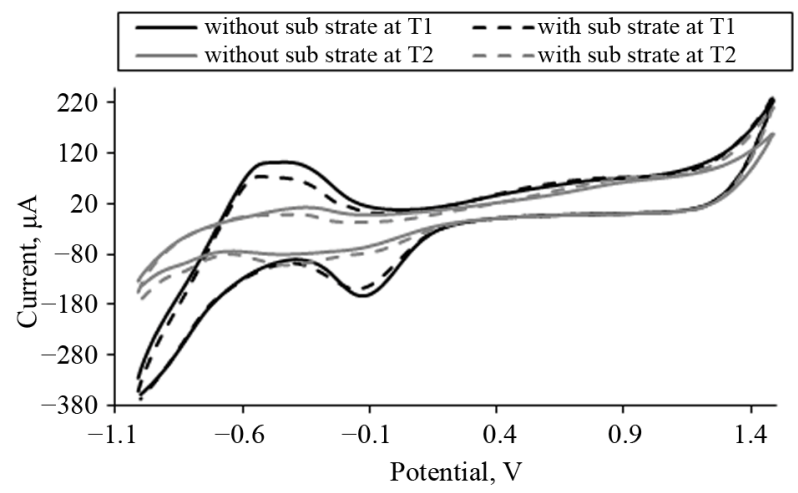

Figure 5. CVs of Pt/POPDA/urease electrode in 0.01 M PBS (pH 5.8) without (solid line) and with (dashed line) $100 \mu \mathrm{L}$ of $1 \mathrm{M}$ urea at two temperatures $\left(\mathrm{T} 1=30^{\circ} \mathrm{C}, \mathrm{T} 2=20^{\circ} \mathrm{C}\right)$.
Figure 5 also presented the effect of two different temperatures $\left(20^{\circ} \mathrm{C}\right.$ and $\left.30^{\circ} \mathrm{C}\right)$ on the CVs of the biosensor. It can be seen that the peak magnitudes were higher at $30^{\circ} \mathrm{C}$ (the optimum temperature of the urease). Therefore, all measurements were carrying out at $30^{\circ} \mathrm{C}$.

$\mathrm{CVs}$ of the Pt/POPDA/urease biosensor in the presence of urea were studied (Figure 6). A constant potential of $-0.1 \mathrm{~V}$ (Figure 6(a)) and $-0.4 \mathrm{~V}$ (Figure 6(b)) was applied to the working electrode and the current was recorded as a function of time until a good baseline was obtained. After equilibration, series of 100 $\mu \mathrm{L}$ of $1 \mathrm{M}$ urea were added to the electrochemical cell, containing $30 \mathrm{~mL}$ of $0.01 \mathrm{M}$ PBS (pH 5.8).

As can be seen from Figure 6 the current (in $\mu \mathrm{A}$ ) increased with the addition of urea which is due to the produced ammonium from the enzymatic reaction, then reached saturation and another portion of urea was added. The results show that this biosensor exhibits an excellent response for urea at working potential of $-0.1 \mathrm{~V}$ with a response time of $1 \mathrm{~min}$. This curve was used for preparation of urea calibration curve (Figure 7).

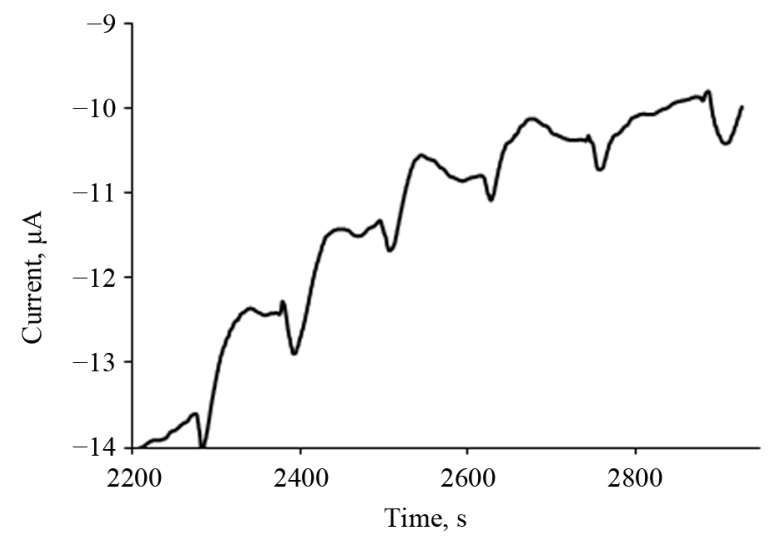

(a)

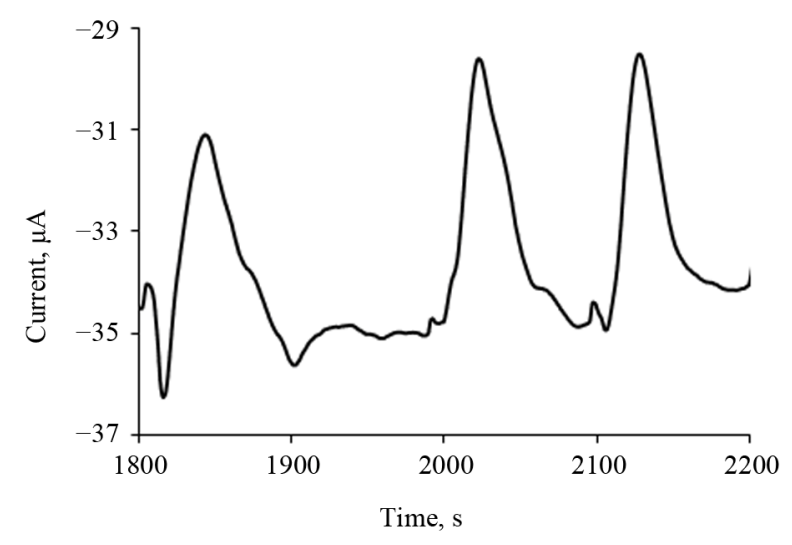

(b)

Figure 6. Chronoamperometric curves of Pt/POPDA/urease biosensor, with successive addition of $100 \mu \mathrm{L}$ of $1 \mathrm{M}$ urea in $0.01 \mathrm{M}$ PBS (pH 5.8) at potential of $-0.1 \mathrm{~V}$ (a) and $-0.4 \mathrm{~V}$ (b). 


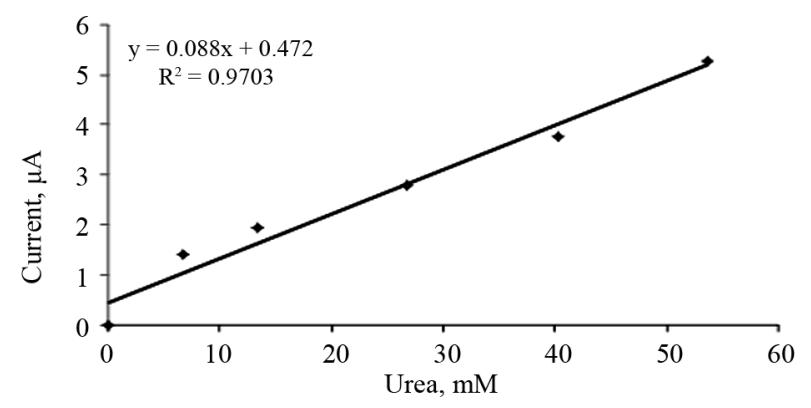

Figure 7. A urea calibration curve of Pt/POPDA/urease biosensor.

It can be seen from Figure 7 that with increasing concentration of urea the amperometric current also increased. A good linear relationship was observed between urea concentration and amperometric current in a concentration range from 6.7 to $54 \mathrm{mM}$ with detection limit of $5 \mathrm{mM}$. The linear regression equation was I $(\mu \mathrm{A})$ $=0.472+0.088$ [urea], $(\mathrm{mM})$ with correlation coefficient $\left(\mathrm{R}^{2}\right)$ of 0.9703 .

\subsection{Preparation of Pt/PPy/Urease Biosensor}

The electropolymerization was carried out in $0.1 \mathrm{M} \mathrm{KCl}$, containing $0.1 \%$ urease and different Py concentration $(0.2$ and $0.4 \mathrm{M})$. The change in the electroactive nature of the PPy film after enzyme entrapment can be directly related to the existence of electrostatic interactions between a bulky, negatively charged enzyme entrapped in a positively charged polymer matrix, where the insertion of cations into the film becomes well established to ensure the electroneutrality of the PPy matrix. The CV curves of electropolymerization of Py and urease entrapment were shown in Figure 8. The number of deposition cycles was 10,20 and 30 cycles.

Figures 8(a) and 8(b) showed that CV curves become wider with the increase of cycle number. These results were due to the increase of polymeric film thickness. The electropolymerization of Py is an anodic oxidation process and due to this process the anodic and cathodic currents increase rapidly [16]. It was found that when the cycle number for preparing PPy film was greater than 30 the diffusion barrier was increasing. Therefore, the optimum number of deposition cycles of PPy was 30 .

Figure 8 also showed that the magnitude of the anodic current was increasing with increasing of pyrrole concentration. When using Py concentration below $0.1 \mathrm{M}$, the electropolymerization was very slow and the obtained film thickness was only acceptable after $30 \mathrm{~min}$. The increasing of the Py concentration over $0.4 \mathrm{M}$ with the same deposition time resulted in a formation of heterogeneous polymers that covered the electrode incomepletely. Therefore, the optimum Py concentration of 0.4 $\mathrm{M}$ was selected.

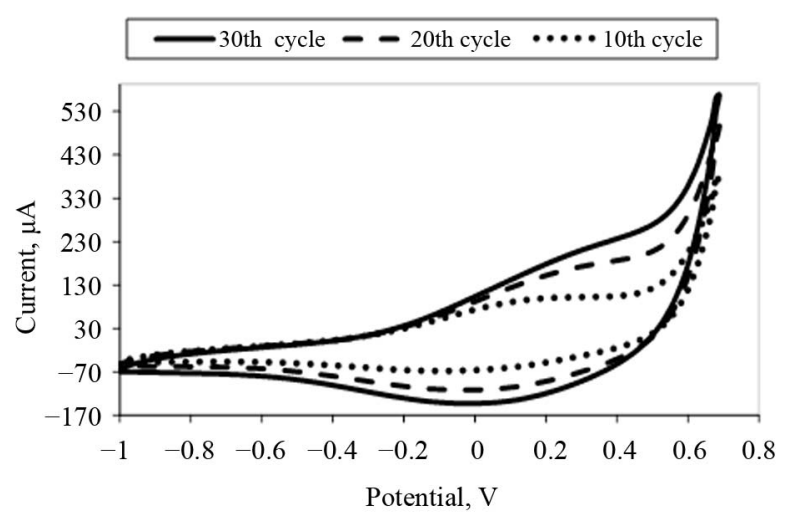

(a)

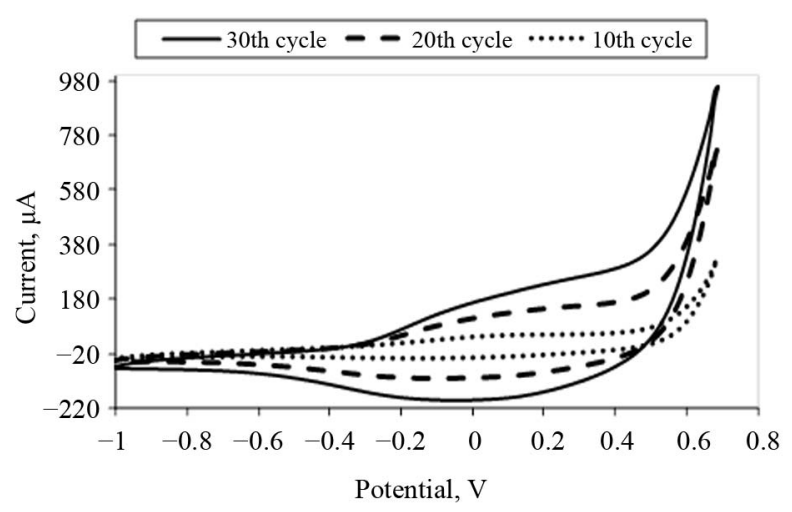

(b)

Figure 8. CV curves of the electropolymerization of (a) 0.2 and (b) $0.4 \mathrm{M} P P y$ in $0.1 \mathrm{M} \mathrm{KCl}$. Scan rate: $0.05 \mathrm{~V} / \mathrm{s}$; potential range: -1.0 to $+0.7 \mathrm{~V}$; (.....) 10th cycles, (- - -) 20th cycles and $(-)$ 30th cycles.

SEM images of the modified Pt/PPy electrode were presented in Figure 9. It can be observed very well the electrodeposited PPy layer and its characteristic structure like as cauliflower. It can be seen that the polymeric film were more density when used $0.4 \mathrm{M}$ Py. This image proves once again the formation of the PPy layer on the platinum electrode surface by cyclic voltammetry and its characteristic structure.

Effect of $\mathrm{pH}$ of the solution on CVs of Pt/PPy electrode was investigated. Figure 10 shows the $\mathrm{CV}$ curves of $\mathrm{Pt} / \mathrm{PPy}$ electrode, obtained at potential range from -1.0 to $+0.7 \mathrm{~V}$ at $\mathrm{pH} 5.6(0.1 \mathrm{M}$ phosphate buffer $), \mathrm{pH}$ $7.6(0.1 \mathrm{M}$ phosphate buffer $)$ and $\mathrm{pH} 10.6(0.1 \mathrm{M}$ glycine buffer), at a scan rate of $0.05 \mathrm{~V} / \mathrm{s}$. The results showed that the $\mathrm{pH}$ change of the system was accompanied by a current change. The anodic and cathodic peaks shift to the more negative potentials as $\mathrm{pH}$ increases. This confirms that electroconductivity of PPy film depends from $\mathrm{pH}$ changes (PPy itself acts as a $\mathrm{pH}$ sensitive indicator). Therefore, the PPy film is suitable matrix for entrapment of urease and would respond to the ammonium produced by urease catalyzed reaction. 


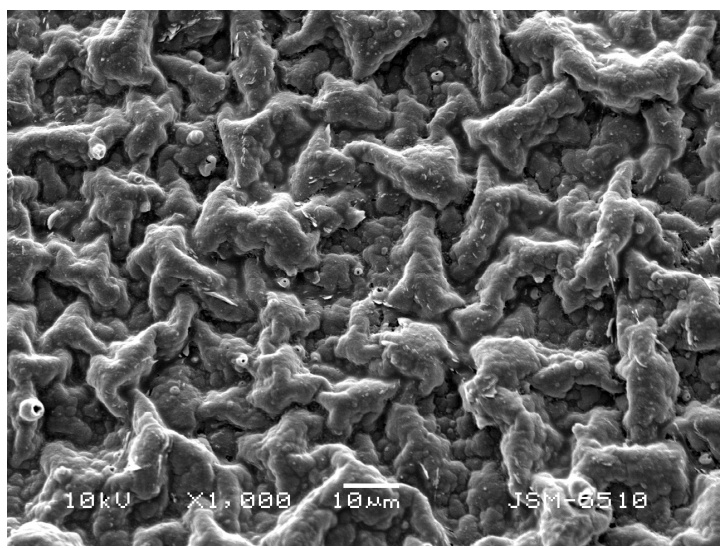

(a)

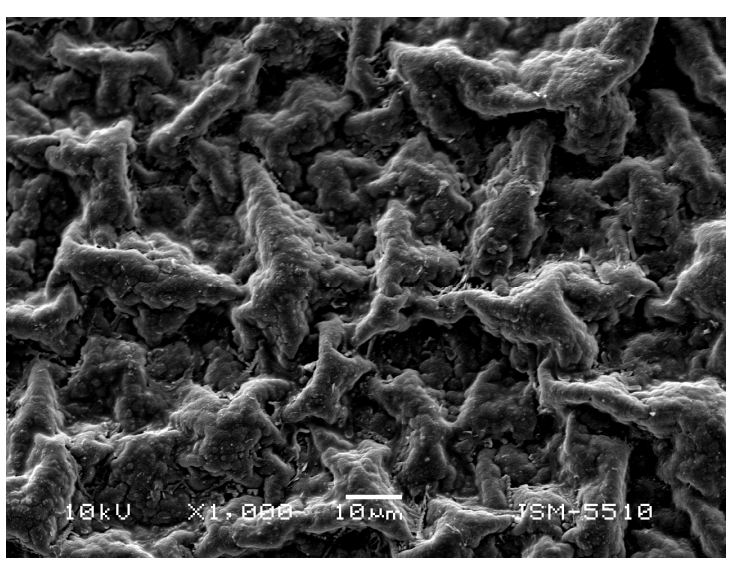

(b)

Figure 9. SEM images of the Pt/PPy/urease electrode at 0.4 $M(a)$ and $0.2 \mathrm{M}$ Py concentration (b).

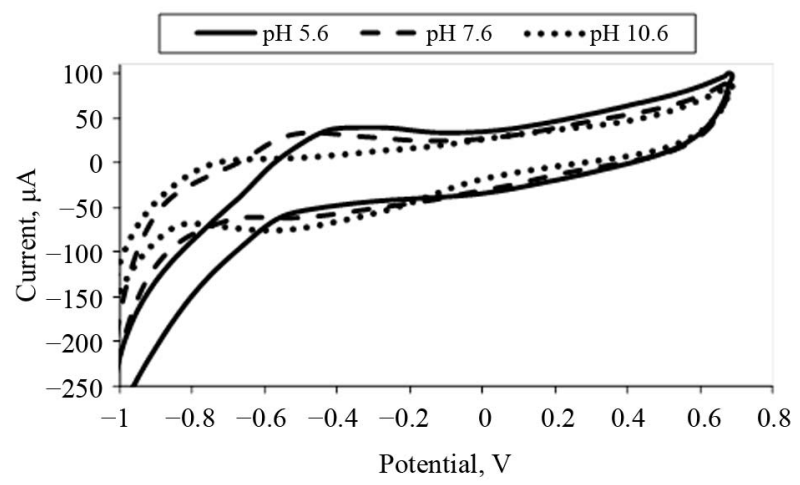

Figure 10. CV curves of Pt/PPy electrode in 0.1 M PBS at pH $5.6(-)$, pH 7.6 (- - - -) and pH 10.6 (....); range from -1.0 to $+0.7 \mathrm{~V}$; at a scan rate of $0.05 \mathrm{~V} / \mathrm{s}$.

The voltammetric response of the PPy/urease film shows that a new, well defined redox couple was established at $0.15 \mathrm{~V}$ and $-0.64 \mathrm{~V}$ vs. $\mathrm{Ag} / \mathrm{AgCl}$ (Figure 11). The changes of the reduction peak with addition of urea clearly showed that the biosensor respond to the urea. Therefore, $-0.6 \mathrm{~V}$ was selected as working potential for carrying out the chronoamperometric measurements.

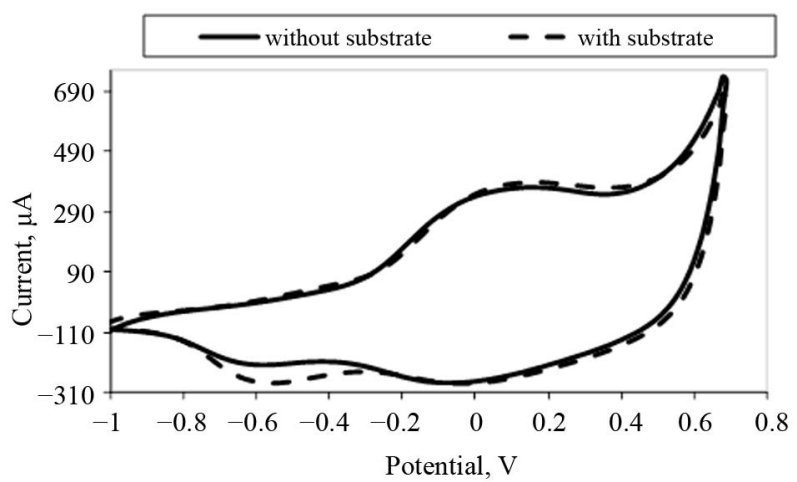

Figure 11. CV curves of Pt/PPy/urease electrode in $0.01 \mathrm{M}$ PBS (pH 5.8) without (solid line) and with (dashed line) 200 $\mu \mathrm{L}$ of $10 \mathrm{mM}$ urea.

The chronoamperometric curves of the Pt/PPy/urease biosensor were studied (Figure 12(a)). The multi-layered urease biosensors were prepared by methodic described above. CNT were incorporated within the growing PPy film for maintaining its electrical neutrality. The entrapment of the CNT has a little effect upon the electropolymerization rate and redox properties of the resulting film. Figure 12 shows the response of $\mathrm{Pt} / \mathrm{PPy} /$ urease biosensor (a) and three PPy modified biosensors: Pt/PPy/CNT/ urease (b), Pt/POPDA/PPy/urease (c) and Pt/PPy/ POPDA/urease (d) to series of $200 \mu \mathrm{L}$ of $10 \mathrm{mM}$ urea added to the electrochemical cell, containing $10 \mathrm{~mL}$ of $0.01 \mathrm{M}$ PBS (pH 5.8). The applied potential was $-0.6 \mathrm{~V}$. As can be seen, the four chronoamperometric curves are similar. With the increasing of urea concentration the amperometric response increased linearly in the range from 0.02 to $0.16 \mathrm{mM}$ urea (Figure 13). It was evident that the PPy biosensor and multi-layered nanostructured urease biosensors measured lower urea concentration, than POPDA biosensor (6.7 to $54 \mathrm{mM}$ ). The comparison of the four urea calibration curves showed that the curve slope of the Pt/PPy/CNT/urease electrode was larger and this electrode had the greatest sensitivity. This was due to the incorporation of CNT in deposited PPy film of the electrode. This is completely understandable since added CNT improve electrical conductivity of the polymer film, the film was more porous and the diffusion of the substrate was more intensive. The sensitivity of Pt/PPy/ urease electrode was on the second place. Pt/PPy/ POPDA/urease electrode has the lowest sensitivity. The linear regression equations and correlation coefficients $\left(\mathrm{R}^{2}\right)$ are also presented (Figure 13). Obviously, the addition of POPDA to the composition of the two biosensors (Pt/PPy/POPDA/urease and Pt/POPDA/PPy/urease) reduced their sensitivity to urea. It can be seen that the four PPy biosensors were much more sensitive to urea than Pt/POPDA/urease biosensor (Figure 7). For instance, $\mathrm{Pt} / \mathrm{PPy} / \mathrm{CNT} /$ urease biosensor and Pt/PPy/urease biosensor (Figure 13) were 173 and 138 times more sensitive 


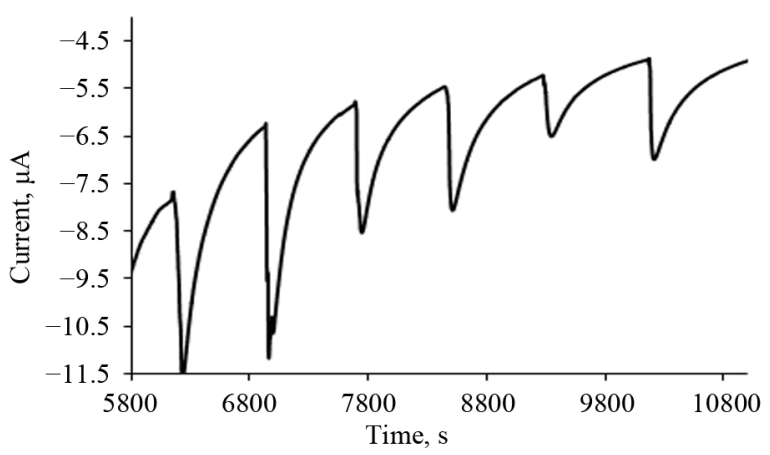

(a)

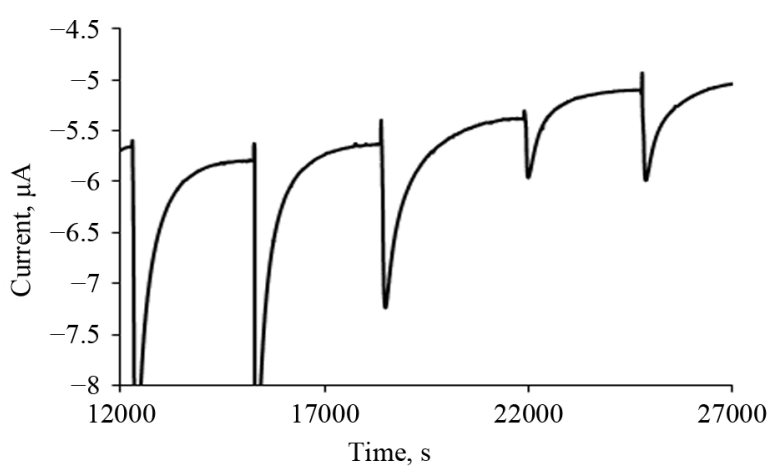

(b)

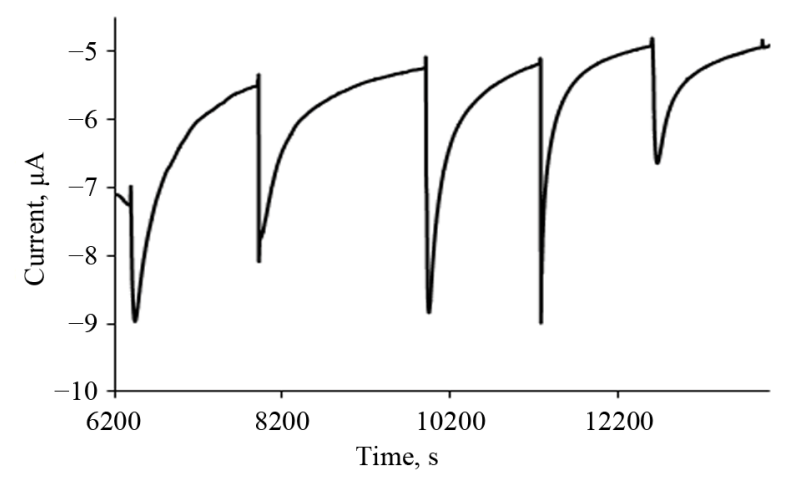

(c)

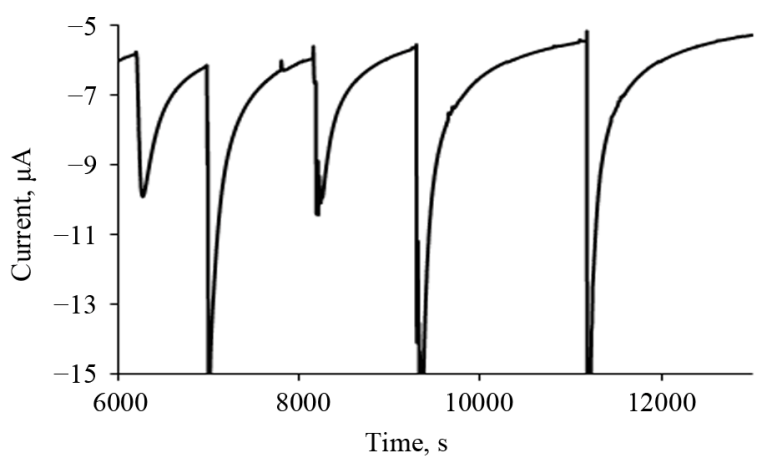

(d)

Figure 12. Chronoamperometric curves of $\mathrm{Pt} / \mathrm{PPy} / \mathrm{urease}$ (a), Pt/PPy/CNT/urease (b), Pt/POPDA/PPy/urease (c) and Pt/PPy/POPDA/urease (d) biosensors with successive adition of $200 \mu \mathrm{L}$ of $10 \mathrm{mM}$ urea in 0.01 M PBS (pH 5.8) at $0.6 \mathrm{~V}$.

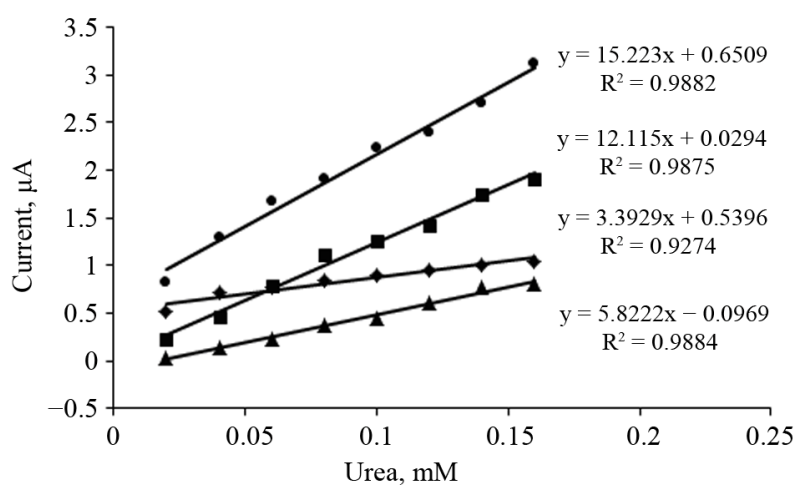

Figure 13. Urea calibration curves of $\mathrm{Pt} / \mathrm{PPy} / \mathrm{CNT} / \mathrm{urease}(\bullet)$, Pt/PPy/urease (ø), Pt/PPy/POPDA/urease ( $\diamond)$ and Pt/POPDA/ PPy/urease (A) biosensors.

Table 1. Comparison of the performance of Pt/PPy/CNT/ urease and Pt/POPDA/urease electrode with urease biosensors obtained by other authors

\begin{tabular}{ccccc}
\hline $\begin{array}{c}\text { Polymeric } \\
\text { film }\end{array}$ & $\begin{array}{c}\text { Linear range of urea } \\
\text { concentrations, } \mathrm{mM}\end{array}$ & $\begin{array}{c}\text { Sensitivity, } \\
\mu \mathrm{A} / \mathrm{mM}\end{array}$ & $\begin{array}{c}\text { Detection } \\
\text { limit, } \mathrm{mM}\end{array}$ & Reference \\
\hline PPy/CNT & $0.02-0.16$ & 15.22 & 0.005 & $\begin{array}{c}\text { Present } \\
\text { study }\end{array}$ \\
POPDA & $6.7-54$ & 5.88 & 5 & $\begin{array}{c}\text { Present } \\
\text { study }\end{array}$ \\
PPy & $0.05-0.25$ & 16.846 & 0.05 & {$[7]$} \\
PPy & $0.0017-0.075$ & - & 0.001 & {$[8]$} \\
P/N & $0.001-1$ & - & 0.0005 & {$[17]$} \\
PMS & $0.5-21$ & 0.022 & 0.2 & {$[18]$} \\
PPy & $1-50$ & - & - & {$[19]$} \\
PAPCP & $0.16-5$ & - & - & {$[20]$} \\
\hline
\end{tabular}

PAPCP—poly (N-3-aminopropyl pyrrole-co-pyrrole); PMS - polymaleimidostyrene; $\mathrm{P} / \mathrm{N}$ - polyaniline-Nafion.

to urea, than Pt/POPDA/urease biosensor (Figure 7). The detection limit of $\mathrm{Pt} / \mathrm{PPy} / \mathrm{CNT} /$ urease biosensor was $0.005 \mathrm{mM}$ urea at a signal-to-noise ratio of 3 . The inter-assay precision of $\mathrm{Pt} / \mathrm{PPy} / \mathrm{CNT} /$ urease biosensor, or fabrication reproducibility was estimated by determining the response to $200 \mu \mathrm{L}$ of $10 \mathrm{mM}$ urea in $0.01 \mathrm{M}$ PBS $(\mathrm{pH} 5.8)$ of six different electrodes and the relative standard deviation was found to be $2.43 \%$. The intra-assay precision of the sensors was evaluated by assaying one enzyme electrode for six replicate determinations and the relative standard deviation was calculated. The obtained biosensor showed storage stability of $70 \%$ of its initial current response after 30 days.

The performance of the constructed biosensor is comparable to the results reported by other authors (see Table 1). The linear range (in $\mathrm{mM}$ ) of the calibration curves obtained with $\mathrm{Pt} / \mathrm{PPy} / \mathrm{CNT} /$ urease biosensor, sensitivity and detection limit are comparable with the results published by other authors (Table 1). 


\section{REFERENCES}

[1] B. Gupta, S. Singh, S. Mohan and R. Prakash, "Urea Biosensor based on Conducting Polymer Transducers," In: P. A. Serra, Ed., Biosensors, InTech, Rijeka, 2010, p. 302.

[2] J. C. Vidal, S. MeÂndez and J. R. Castillo, "Electropolymerization of Pyrrole and Phenylenediamine over an Organic Conducting Salt Based Amperometric Sensor of Increased Selectivity for Glucose Determination," Analytica Chimica Acta, Vol. 385, No. 1-3, 1999, pp. 203211. doi:10.1016/S0003-2670(98)00837-X

[3] S. Vishwanath, J. Wang, L. G. Bachas, D. A. Butterfield and D. Bhattacharyya, "Site-Directed and Random Immobilization of Subtilisin on Functionalized Membranes: Activity Determination in Aqueous and Organic Media," Biotechnology and Bioengineering, Vol. 60, No. 5, 1998, pp. 608-616. doi:10.1002/(SICI)1097-0290(19981205)6

[4] Y. Yao and K. K. Shiu, "Electron-Transfer Properties of Different Carbon Nanotube Materials, and Their Use in Glucose Biosensors," Analytical and Bioanalytical Chemistry, Vol. 387, No. 1, 2007, pp. 303-309. doi:10.1007/s00216-006-0924-1

[5] J. C. Soares, A. Brisolari, V. C. Rodrigues, E. A. Sanches and D. Gonçalves, "Amperometric Urea Biosensors Based on the Entrapment of Urease in Polypyrrole Films," Reactive and Functional Polymers, Vol. 72, No. 2, 2012, pp. 148-152. doi:10.1016/i.reactfunctpolym.2011.12.002

[6] M. P. Massafera and S. I. C. Torresi, "Urea Amperometric Biosensors Based on Nanostructured Polypyrrole," Electroanalysis, Vol. 23, No. 11, 2011, pp. 2534-2540. doi:10.1002/elan.201100239

[7] S. B. Adeloju, S. J. Shaw and G. G. Wallace, "Polypyrrole-Based Amperometric Flow Injection Biosensor for Urea," Analytica Chimica Acta, Vol. 323, No. 1-3, 1996, pp. 107-113. doi:10.1016/0003-2670(95)00562-5

[8] S. Adeloju, S. Shaw and G. Wallace, "Pulsed-Amperometric Detection of Urea in Blood Samples on a Conducting Polypyrrole-Urease Biosensor," Analytica Chimica Acta, Vol. 341, No. 2-3, 1997, pp. 155-160. doi:10.1016/S0003-2670(96)00502-8

[9] M. P. Massafera and S. I. C. de Torresi, "Urea Amperometric Biosensors Based on a Multifunctional Bipolymeric Layer: Comparing Enzyme Immobilization Methods," Sensors and Actuators B: Chemical, Vol. 137, No. 2, 2009, pp. 476-482. doi:10.1016/j.snb.2009.02.013

[10] M. Stred'anskýa, A. Pizzariello, S. Stred'anská and S. Miertuš, "Amperometric pH-Sensing Biosensors for Urea, Penicillin, and Oxalacetate," Analytica Chimica Acta, Vol. 415, No. 1-2, 2000, pp. 151-157. doi:10.1016/S0003-2670(00)00869-2

[11] D. Chirizzi and C. Malitesta, "Potentiometric Urea Bio- sensor Based on Urease Immobilized by an Electrosynthesized Poly (o-Phenylenediamine) Film with Buffering Capability," Sensors and Actuators B: Chemical, Vol. 157, No. 1, 2011, pp. 211-215. doi:10.1016/j.snb.2011.03.051

[12] F. Branzoi, V. Branzoi and A. Musina, "Amperometric Urea Biosensor Based on Platinum Electrode Modified with a Nanocomposite Film," Surface and Interface Analysis, Vol. 44, No. 8, 2012, pp. 895-898. doi:10.1002/sia.4861

[13] J. Wang and M. Musameh, "Carbon-Nanotubes Doped Polypyrrole Glucose Biosensor," Analytica Chimica Acta, Vol. 539, 2005, No. 1-2, pp. 209-213. doi:10.1016/j.aca.2005.02.059

[14] G. Gustafsson, I. Lundstrom, B. Liedberg, C. R. Wu and O. Inganas, "The Interaction between Ammonia and Poly (Pyrrole)," Synthetic Metals, Vol. 31, No. 2, 1989, pp. 163-179. doi:10.1016/0379-6779(89)90812-6

[15] M. Vidotti, L. H. Dall'Antonia, E. P. Cintra and S. I. C. Torresi, "Reduction of Interference Signal of Ascorbate and Urate in Poly(Pyrrole)-Based Ammonia Sensors in Aqueous Solutions," Electrochimica Acta, Vol. 49, No. 22-23, 2004, pp. 3665-3670. doi:10.1016/j.electacta.2003.11.034

[16] V. Branzoi, F. Golgovicia and F. Branzoi, "Electronically Conductive Polymers Type Polypyrrole and Polyaniline Obtained by Electropolymerization onto Aluminium Substrate," Revue Roumaine de Chimie, Vol. 53, No. 7, 2008, pp. 553-561.

http://revroum.getion.ro/wp-content/uploads/2008/RRCh _7_2008/Art\%2007.pdf

[17] W.-J. Cho and H.-J. Huang, “An Amperometric Urea Biosensor Based on a Polyaniline-Perfluorosulfonated Ionomer Composite Electrode," Analytical Chemistry, Vol. 70, No. 18, 1998, pp. 3946-3951. doi:10.1021/ac980004a

[18] X. Wang, H. Watanabe, N. Sekioka, H. Hamana and S. Uchiyama, "Amperometric Urea Biosensor Using Aminated Glassy Carbon Electrode Covered with Urease Immobilized Carbon Sheet, Based on the Electrode Oxidation of Carbamic Acid," Electroanalysis, Vol. 19, No. 12, 2007, pp. 1300-1306. doi:10.1002/elan.200603853

[19] P. P. Mishra, "Conducting Polymer-Coated Enzyme Microsensor for Urea," Analyst, Vol. 113, No. 2, 1988, pp. 329-331. doi:10.1039/an9881300329

[20] Rajesh, V. Bisht, W. Takashima and K. Kaneto, “An Amperometric Urea Biosensor Based on Covalent Immobilization of Urease onto an Electrochemically Prepared Copolymer Poly(N-3-aminopropyl pyrrole-co-pyrrole) Film," Biomaterials, Vol. 26, No. 17, 2005, pp. 3683-3690. doi:10.1016/j.biomaterials.2004.09.024 